\title{
National trends in hospitalization and mortality rates for patients with HIV, HCV, or HIV/HCV coinfection from 1996-2010 in the United States: a cross-sectional study
}

\author{
Christine U Oramasionwu ${ }^{1 *}$, Joshua C Toliver ${ }^{1}$, Terence L Johnson ${ }^{1}$, Heather N Moore ${ }^{1}$ and Christopher R Frei ${ }^{2,3}$
}

\begin{abstract}
Background: The comparative impact of chronic viral monoinfection versus coinfection on inpatient outcomes and health care utilization is relatively unknown. This study examined trends, inpatient utilization, and hospital outcomes for patients with HIV, HCV, or HIV/HCV coinfection.

Methods: Data were from the 1996-2010 National Hospital Discharge Surveys. Hospitalizations with primary ICD-9-CM codes for HIV or HCV were included for HIV and HCV monoinfection, respectfully. Coinfection included both HIV and HCV codes. Demographic characteristics, select comorbidities, procedural interventions, average hospital length of stay (LOS), and discharge status were compared by infection status (HIV, HCV, HIV/HCV). Annual disease estimates and survey weights were used to generate hospitalization rates.

Results: $\sim 6.6$ million hospitalizations occurred in patients with HIV (39\%), HCV (56\%), or HIV/HCV (5\%). The hospitalization rate (hospitalizations per 100 persons with infection) decreased in the HIV group (29.8 in 1996; 5.3 in 2010), decreased in the HIV/HCV group (2.0 in 1996; 1.5 in 2010), yet increased in the HCV group (0.2 in 1996; 0.9 in 2010). Median LOS from 1996 to 2010 (days, interquartile range) decreased in all groups: HIV, 6 (3-10) to 4 (3-8); HCV, 5 (3-9) to 4 (2-6); HIV/HCV, 6 (4-11) to 4 (2-7). Age-adjusted mortality rates decreased for all three groups. The rate of decline was least pronounced for those with HCV monoinfection.

Conclusion: Hospitalizations have declined more rapidly for patients with HIV infection (including HIV/HCV coinfection) than for patients with HCV infection. This growing disparity between HIV and HCV underscores the need to allocate more resources to HCV care in hopes that similar large-scale improvements can also be accomplished for patients with HCV.
\end{abstract}

Keywords: HIV, HCV, Coinfection, Hospitalization, Health care utilization

\section{Background}

Human Immunodeficiency Virus (HIV) monoinfection and hepatitis $\mathrm{C}$ virus (HCV) monoinfection have been the subject of much research over the past two decades; however, HIV/HCV coinfection is a growing medical concern in the U.S. [1]. Combination HIV antiretroviral therapy and combination $\mathrm{HCV}$ antiviral therapy have been recommended since the 1990s, as the respective

\footnotetext{
* Correspondence: oramsc@email.unc.edu

'Division of Pharmaceutical Outcomes and Policy, University of North Carolina, UNC Eshelman School of Pharmacy, 2215 Kerr Hall, Chapel Hill, NC 27599-7573, USA

Full list of author information is available at the end of the article
}

treatment regimens greatly reduce patient morbidity and mortality [2,3]. While HIV antiretroviral and HCV antiviral therapies are widely recommended for use in patients with HIV/HCV coinfection [4], these patients continue to experience poorer health outcomes than their counterparts with monoinfection. For instance, in the inpatient setting, patients with coinfection are at increased risk for accelerated progression of liver disease and increased rates of morbidity and mortality, as compared to patients with HIV or HCV monoinfection [5,6].

However, since these combination therapies became available, few studies have documented how health care utilization patterns differ for patients with coinfection 
versus monoinfection. Thus, the burden that patients with coinfection place on the U.S. inpatient health care delivery system, as compared to patients with monoinfection, is relatively unknown. This study chronicled and compared inpatient health care utilization, including hospitalization rates, median length of hospital stay (LOS), and patient mortality rates, for patients with $\mathrm{HIV}, \mathrm{HCV}$, or $\mathrm{HIV} / \mathrm{HCV}$ coinfection.

\section{Methods}

This was a nationally representative, retrospective, observational study using data from the National Hospital Discharge Survey (NHDS) for the years 1996 through 2010. These surveys contain data for approximately 270,000 hospital discharges per year from 500 general and pediatric hospitals while excluding federal, military, veteran affairs, and institutional hospitals (e.g., prison hospitals). Demographic data include patient age, sex, race, hospital geographic region, hospital bed size, and patient insurance status. The survey is available to the public and is a national representation of annual discharge records. Each record consists of up to seven International Classification of Diseases, Ninth Revision, Clinical Modification (ICD-9-CM) diagnosis codes, as well as up to four procedure codes.

Hospitalizations primarily related to $\mathrm{HIV}, \mathrm{HCV}$, or $\mathrm{HIV} / \mathrm{HCV}$ were included in this analysis. The following ICD-9-CM codes were used: HIV infection (042, V08, 079.53) and HCV infection (070.41, 070.44, 070.51, 070.54, 070.70, 070.71). HIV monoinfection hospitalizations excluded HCV codes and HCV monoinfection hospitalizations excluded HIV codes. HIV/HCV coinfection hospitalizations included those that had ICD-9-CM codes for both HIV and HCV. Procedural interventions were identified using ICD-9-CM procedure codes. Patients $<15$ years of age at the time of hospitalization were excluded from this analysis. Variables from the NHDS included patient demographics (patient age at time of hospitalization [years], race, gender, insurance status) as well as hospitalization characteristics (discharge diagnosis, hospital geographic region in the U.S., year of hospitalization, hospital discharge status, and LOS [days]). Other comorbidities, such as hepatitis B virus infection, illicit drug use, alcohol use, and Charlson co-morbidity index scores, were determined based on other diagnosis codes.

All data were analyzed using JMP $9.0^{\circ}$ (SAS Corp, Cary, NC). Normally distributed continuous variables were expressed as means ( \pm standard deviation) and categorical variables as percentages. Demographic characteristics and select comorbidities were compared by patient infection status (HIV, HCV, and HIV/HCV). The chi-square test was used for comparisons of categorical variables and the Student's t-test was used for comparison of continuous variables. Annual population-level estimates for HIV monoinfection, HCV monoinfection, and HIV/HCV coinfection were computed to generate annual hospitalization rates. The U.S. Standard Million Population 2000 age distribution was used to calculate age-adjusted mortality rates. The University of North Carolina Office of Human Research Ethics determined that this project was not considered Human Subjects Research according to regulatory criteria; therefore, institutional review board approval was not needed.

\section{Results}

Between 1996 and 2010, approximately 6.6 million hospitalizations met study criteria. Of these, 2,548,404 (39\%) occurred in the group with HIV infection, $3,707,776$ (56\%) occurred in the group with HCV infection, and 317,307 (5\%) occurred in the group with $\mathrm{HIV} / \mathrm{HCV}$ coinfection (Table 1). Those with HCV were older in age, predominantly of white race, and had a higher percentage of females than those with HIV or HIV/HCV. In contrast, those with HIV were mostly of black race and were predominately from the southern United States. Those with coinfection were mostly of black race and were primarily Medicare insurance recipients. Comorbidities were distributed across the three groups ( $\mathrm{HIV}, \mathrm{HCV}$, $\mathrm{HIV} / \mathrm{HCV})$ as follows: hepatitis B $(2 \%, 5 \%, 10 \%)$, illicit drug use $(15 \%, 17 \%, 24 \%)$, and alcohol use $(9 \%, 19 \%$, $13 \%)$. Overwhelmingly, inpatient care occurred in nonprofit hospitals $(70 \%, 71 \%$ and $68 \%$ for HIV, HCV and $\mathrm{HIV} / \mathrm{HCV}$, respectfully). Most hospitalizations occurred in larger facilities. Inpatient procedures were distributed across the three groups (HIV, HCV, HIV/HCV) as follows: transfusion $(8 \%, 9 \%, 8 \%)$, central line placement $(8 \%, 8 \%$, $8 \%)$, lumbar puncture $(7 \%, 1 \%, 5 \%)$, bronchoscopy $(5 \%, 1 \%$, $3 \%)$, and upper GI endoscopy (4\%, 6\%, 4\%). The majority of hospitalized patients were routinely discharged home (Table 2).

Over the 15 years examined, the hospitalization rate (hospitalizations per 100 persons with infection) decreased in the HIV group (29.8 in 1996; 5.3 in 2010) and decreased slightly in the HIV/HCV group (2.0 in 1996; 1.5 in 2010) (Figure 1). The age-adjusted hospital mortality rates (per 100,000 population) over the same time interval decreased for all three groups; however, the rate of decline was least pronounced in the $\mathrm{HCV}$ group (Figure 2). The magnitude of the decreases ordered from greatest to least were as follows: HIV/HCV (10,098 in 1996; 661 in 2010), HIV (6,874 in 1996; 1,855 in 2010) and the smallest decrease for $\operatorname{HCV}(2,773$ in 1996; 1,589 in 2010). From 1996 to 2010, median LOS (interquartile range) decreased in all groups: HIV group, 6 days (3-10) to 4 days (3-8); HCV group, 5 days (3-9) to 4 days (2-6); and HIV/HCV group, 6 days (4-11) to 4 days (2-7) (Figure 3). 
Table 1 Comparison of demographics, select comorbidities, and hospital characteristics for patients with HIV, HCV, or HIV/HCV

\begin{tabular}{|c|c|c|c|}
\hline Characteristic & $\begin{array}{c}\text { HIV } \\
(n=2,548,404)\end{array}$ & $\begin{array}{c}\text { HCV } \\
(n=3,707,776)\end{array}$ & $\begin{array}{c}\text { HIV } / \mathrm{HCV} \\
(\mathrm{n}=317,307)\end{array}$ \\
\hline Demographics & - & - & - \\
\hline Age (yrs), mean $\pm S D$ & $42 \pm 10$ & $50 \pm 12$ & $45 \pm 8$ \\
\hline Gender & - & - & - \\
\hline Female & $34 \%$ & $39 \%$ & $31 \%$ \\
\hline Male & $66 \%$ & $61 \%$ & $69 \%$ \\
\hline Race/ethnicity & - & - & - \\
\hline White & $28 \%$ & $57 \%$ & $35 \%$ \\
\hline Black & $52 \%$ & $19 \%$ & $45 \%$ \\
\hline Other & $20 \%$ & $24 \%$ & $20 \%$ \\
\hline Geographic region & - & - & - \\
\hline South & $44 \%$ & $38 \%$ & $38 \%$ \\
\hline West & $12 \%$ & $24 \%$ & $13 \%$ \\
\hline Northeast & $33 \%$ & $24 \%$ & $40 \%$ \\
\hline Midwest & $11 \%$ & $14 \%$ & $9 \%$ \\
\hline Insurance & - & - & - \\
\hline Private & $19 \%$ & $24 \%$ & $12 \%$ \\
\hline Medicare & $24 \%$ & $27 \%$ & $22 \%$ \\
\hline Medicaid & $40 \%$ & $30 \%$ & $47 \%$ \\
\hline Other/unknown & $17 \%$ & $19 \%$ & $19 \%$ \\
\hline Comorbidities & - & - & - \\
\hline Hepatitis B virus & $2 \%$ & $5 \%$ & $10 \%$ \\
\hline Illicit drug use & $15 \%$ & $17 \%$ & $24 \%$ \\
\hline Alcohol use & $9 \%$ & $19 \%$ & $13 \%$ \\
\hline $\begin{array}{l}\text { Charlson Score, } \\
\text { mean } \pm \text { SD }\end{array}$ & $3.4 \pm 2.6$ & $1.5 \pm 1.3$ & $3.1 \pm 2.6$ \\
\hline Hospital ownership & - & - & - \\
\hline Proprietary & $7 \%$ & $10 \%$ & $7 \%$ \\
\hline Government & $23 \%$ & $19 \%$ & $25 \%$ \\
\hline $\begin{array}{l}\text { Nonprofit, including } \\
\text { church }\end{array}$ & $70 \%$ & $71 \%$ & $68 \%$ \\
\hline Hospital bedsize & - & - & \\
\hline$<100$ beds & $7 \%$ & $15 \%$ & $5 \%$ \\
\hline 100-199 & $13 \%$ & $21 \%$ & $11 \%$ \\
\hline $200-299$ & $16 \%$ & $18 \%$ & $16 \%$ \\
\hline $300-499$ & $35 \%$ & $27 \%$ & $35 \%$ \\
\hline$\geq 500$ & $29 \%$ & $19 \%$ & $32 \%$ \\
\hline
\end{tabular}

\section{Discussion}

To our knowledge, this is the first study to chronicle and compare inpatient health care utilization for patients with $\mathrm{HIV}, \mathrm{HCV}$, or $\mathrm{HIV} / \mathrm{HCV}$ over a long period of time (1996-2010). Our study reveals that there is a growing disparity in inpatient health care utilization for patients with $\mathrm{HCV}$ monoinfection, as compared to patients with HIV monoinfection or $\mathrm{HIV} / \mathrm{HCV}$ coinfection. While age-adjusted patient mortality rates decreased for all three groups, the rate of decline in mortality was least pronounced in patients with $\mathrm{HCV}$ monoinfection. These findings suggest that patients with $\mathrm{HCV}$ infection disproportionately rely on inpatient care as compared to patients with HIV infection.

In general, those with $\mathrm{HCV}$ monoinfection were older in age and a greater proportion were female and of white race, while those with HIV (either monoinfection or coinfection) were younger in age and were predominately of black race. These demographic differences are consistent with results from studies by Ananthakrishnan et al. [5], which compared hospitalizations for patients with $\mathrm{HIV}, \mathrm{HCV}$, or HIV/HCV in the 2006 Nationwide Inpatient Sample (NIS), and by Backus et al. [7], which compared demographic characteristics in veterans with HIV monoinfection and veterans with $\mathrm{HIV} / \mathrm{HCV}$ coinfection. As expected, our study found that the majority of hospitalizations occurred within nonprofit hospitals (bed size greater than 300) and were financed by public insurance. Hospitalizations with HIV or HCV monoinfection occurred more frequently within the southern region, whereas hospitalizations with coinfection occurred more frequently within the Northeast. Our study findings are representative of national trends in HIV and $\mathrm{HCV}$ populations.

One of the study objectives was to chronicle hospital outcomes, patient mortality, and hospital LOS, by infection status. Crude age-adjusted patient mortality decreased in all three groups, but the decrease in mortality was least pronounced for those with $\mathrm{HCV}$ monoinfection. Emerging data demonstrate rising mortality rates in persons with HCV [8,9]. Using 1999-2007 death certificate data from the National Center for Health Statistics, Ly et al. examined and compared mortality rates attributable to HIV and to $\mathrm{HCV}$ [9]. Their analysis revealed that mortality rates during this time frame decreased for individuals with HIV, yet increased for individuals with HCV. There was a decrease of 0.21 deaths per 100,000 persons per year for HIV $(p=0.001)$, yet an increase in the annual age-adjusted mortality rate of 0.18 deaths per 100,000 persons per year for $\mathrm{HCV}(p=0.002)$. By the end of their study period, HCV superseded HIV as a cause of death. While the decrease in average hospital LOS in the present study was less pronounced for those with $\mathrm{HCV}$ monoinfection, the decrease in hospital LOS throughout the study was relatively similar across all three groups. Gebo et al. studied hospitalization rates and intensive care unit utilization in a prospective cohort of individuals with HIV infection through the Johns Hopkins University AIDS Service in Baltimore, MD from 1995-2000 [6]. Mean hospital LOS was 7 days for both 
Table 2 Discharge status for hospitalized patients with HIV, HCV, or HIV/HCV

\begin{tabular}{lccc}
\hline Discharge status & HIV & HCV & HIV/HCV \\
\hline Routine/discharged home & $73 \%$ & $77 \%$ & $72 \%$ \\
Left against medical advice & $5 \%$ & $4 \%$ & $6 \%$ \\
Short-term care transfer & $3 \%$ & $4 \%$ & $3 \%$ \\
Long-term care transfer & $7 \%$ & $6 \%$ & $6 \%$ \\
Alive, not stated & $5 \%$ & $5 \%$ & $7 \%$ \\
Dead & $4 \%$ & $3 \%$ & $3 \%$ \\
Status not stated & $3 \%$ & $1 \%$ & $3 \%$ \\
\hline
\end{tabular}

the HIV and HIV/HCV cohorts [6]. This is in contrast to Ananthakrishnan et al.'s 2006 NIS study, where average hospital LOS was slightly lower in patients with $\mathrm{HIV} / \mathrm{HCV}$ coinfection than in patients with HIV monoinfection ( -0.4 days, $95 \%$ CI -0.58 to -0.14 ) [5]. Despite past discordances in hospital LOS, this particular outcome appears to have improved for patients with monoinfection and for patients with coinfection in recent years.

This study adds to the evidence that HCV infection is placing a growing burden on the inpatient health care system. In the aforementioned study by Gebo et al., hospitalization rates for the HIV monoinfected cohort were approximately 60 hospitalizations per 100 personyears in 1995 [6]. Yet by 1996, hospitalization rates had already decreased by one-third for these patients $(p<0.001)$, with rates remaining stable for the duration of the study. In contrast, rates increased significantly for the individuals with $\mathrm{HIV} / \mathrm{HCV}$ coinfection, rising from 55.4 hospitalizations per 100 person-years in 1995 to 62.9 per 100 person-years in $2000(p=0.001)$ [6]. More recently, Sie et al. conducted a study of Los Angeles County residents who were hospitalized between 2007 and 2009 [10]. There was an increasing number of HCV-related hospitalizations in this region, leading the authors to conclude that $\mathrm{HCV}$ infection was becoming a growing economic burden on government resources due to rising costs of inpatient care required for these patients. Collectively, these findings emphasize the growing need for inpatient resource utilization in this patient population.

In 2007, Ly et al. documented a shift in mortality burden from HIV patients to HCV patients [9]. Prior investigations have documented differences in hospitalization rates for these patient populations. Ananthakrishnan et al.'s study of the 2006 NIS was a nationally representative evaluation of hospital outcomes for patients with HIV, HCV, or HIV/ HCV [5]. Similar to the present study, the investigators compared hospitalizations rates across the three groups. Hospitalization rates in 2006 (hospitalizations per 100 persons) were as follows: HIV (19.9), HCV (14.8) and HIV/ HCV (23.5). In comparison, hospitalization rates in 2006 (hospitalizations per 100 persons) for the present study were as follows: HIV (11), HCV (0.5), and HIV/HCV (4.7). Our lower rates are likely explained by the fact that we restricted our analysis to hospitalizations primarily related to HIV, $\mathrm{HCV}$ or $\mathrm{HIV} / \mathrm{HCV}$, whereas the previous study included all hospitalizations for individuals with these infections. A consistent result in both studies is that hospitalization rates for both HIV and HIV/HCV were greater than those for HCV. Unlike the Ananthakrishnan et al. study, we trended these

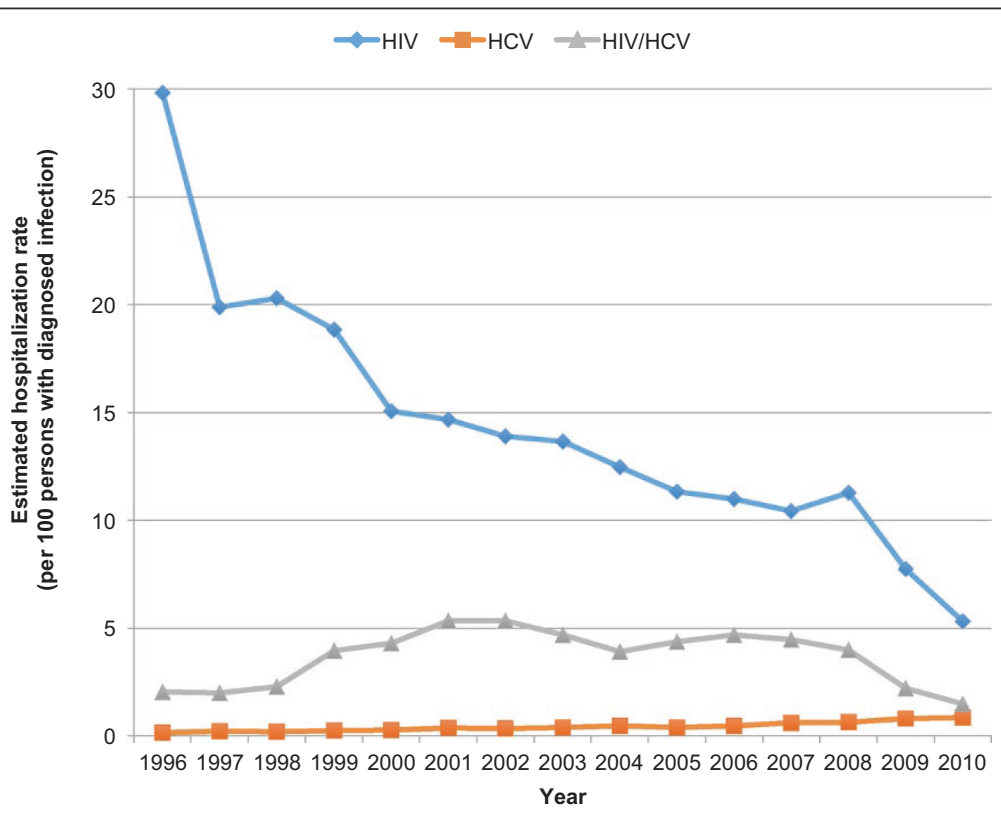

Figure 1 Trends in hospitalization rates for HIV monoinfection, HCV monoinfection, or HIV/HCV coinfection. 


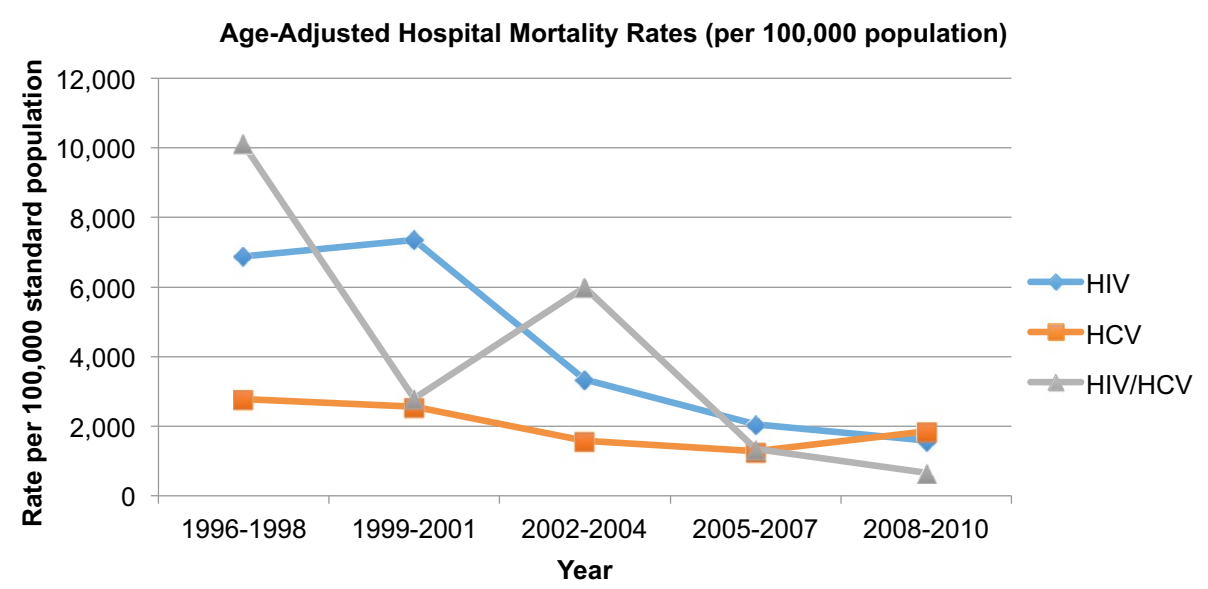

Figure 2 Trends in age-adjusted hospital mortality rates for patients with HIV, HCV, or HIV/HCV.

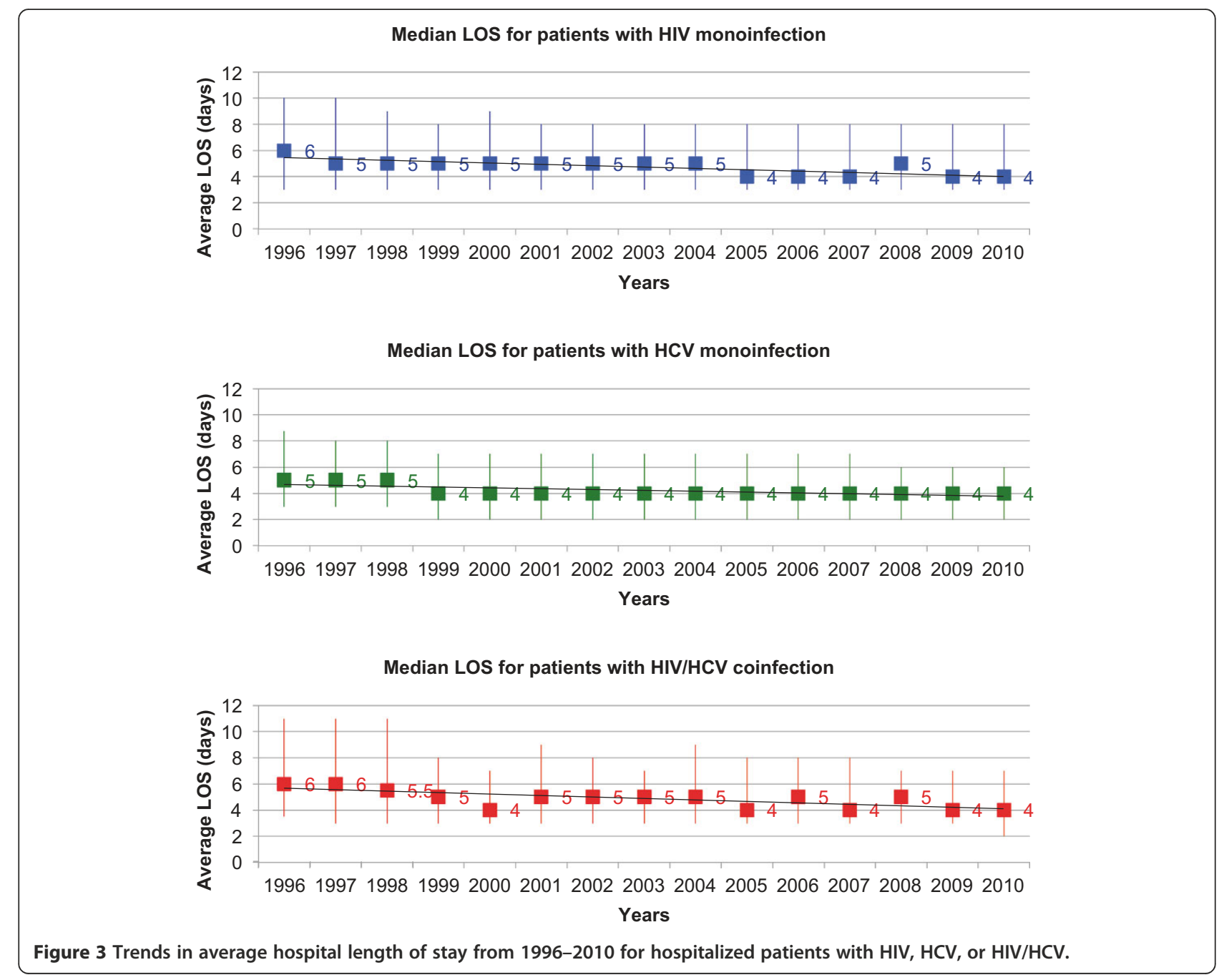


rates over time to assess the differential burden of inpatient health care utilization for the different types of infection.

Our study also compared inpatient procedures as a component of inpatient health care utilization. Similar to Ananthakrishnan et al.'s NIS study, transfusion and central line placement were the most common inpatient interventions in all three groups [5]. Other procedural interventions varied consistently by infection status and are likely attributable to the need for diagnostic and prognostic testing for opportunistic infections. For example, the higher prevalence of lumbar puncture for those with HIV infection is likely explained by the need for cerebrospinal fluid evaluation for neurosyphilis or cryptococcal meningitis in these patients [11-13]. Similarly, the higher prevalence of bronchoscopy is likely explained by Pneumocystis pneumonia (PCP) work-up [13].

The uneven therapeutic advancements in HIV antiretroviral and HCV antiviral therapy may have led to disproportionate improvements in HIV patients compared to HCV patients. There have been numerous advances to HIV treatment, including the advent of highly active antiretroviral therapy (HAART) nearly two decades ago [2]. In contrast, combination therapy with interferon and ribavirin has been the standard therapy for $\mathrm{HCV}$ treatment for many years, despite the limited clinical effectiveness of the regimen [14]. Newer, direct acting antivirals (DAAs) for $\mathrm{HCV}$, namely telaprevir and boceprevir, were only approved for the treatment of $\mathrm{HCV}$ in 2011 and sofosbuvir and simeprevir were most recently approved in late 2013 [15-18]. In addition, HIV has been in the forefront of public health issues for the past few decades and has been the focus of several government-sponsored initiatives. Examples of such initiatives include the U.S. President's Emergency Plan for AIDS Relief (PEPFAR), funding through the Ryan White HIV/AIDS drug assistance program, and the CDC's recommendations for HIV opt-out testing. The disparity between outcomes in HIV and HCV underscores the need to allocate more resources to $\mathrm{HCV}$ care in hopes that similar large-scale improvements can also be accomplished for this patient population.

This study is subject to some limitations. Foremost, this was a retrospective study using cross-sectional data. The observations only represent one specific point in time; a temporal relationship with long-term outcomes could not be determined. Medication information is not available in the NHDS; therefore, it was not possible to characterize treatment utilization (HCV antiviral therapy or HIV antiretroviral therapy). The data presented do not necessarily represent individual patients; rather the data represent individual hospitalizations. The study is unable to characterize or quantify the financial impact on the inpatient system regarding $\mathrm{HIV}, \mathrm{HCV}$, or $\mathrm{HIV} / \mathrm{HCV}$ hospitalizations. Lastly, the study period (1996-2010) was selected to assess how inpatient care utilization and hospital outcomes changed during a time when both HAART and HCV combination antiviral therapy were available. However, this study does not capture recent outcomes reflective of newer $\mathrm{HCV}$ triple therapy regimens since the new DAAs were only approved for use in 2011 and 2013.

\section{Conclusions}

Hospitalizations have declined more rapidly for patients with $\mathrm{HIV}$ infection (including $\mathrm{HIV} / \mathrm{HCV}$ coinfection) than for patients with HCV monoinfection. This growing disparity between HIV and HCV underscores the need to allocate more resources to $\mathrm{HCV}$ care in hopes that similar large-scale improvements can also be accomplished for patients with $\mathrm{HCV}$.

Competing interests

The authors declare that they have no competing interests.

\section{Authors' contributions}

CUO had full access to all the data in the study and takes responsibility for the integrity of the data and the accuracy of study findings. CRF and CUO were involved in the study design and implementation. CUO, JCT, TL, and HNM were involved in data acquisition and cleaning. CUO conducted the data analysis. CUO, CRF, JCT, TLJ, and HNM were involved in the interpretation of study findings. CUO, CRF, JCT, TLJ, and HNM helped revise the manuscript. All authors read and approved the final version of the manuscript.

\section{Acknowledgements}

This study was funded by The University of North Carolina Junior Faculty Development Award, awarded to Dr. Oramasionwu. Dr. Oramasionwu was also supported in part by the NIH Loan Repayment Program (LRP) through the National Institute on Minority Health and Health Disparities (Grant number: L60 MD003770). Additionally, parts of this study were presented at the 2012 and 2013 annual IDWeek meetings in San Diego, CA (October 17-21, 2012) and San Francisco, CA (October 2-6, 2013).

\section{Author details}

${ }^{1}$ Division of Pharmaceutical Outcomes and Policy, University of North Carolina, UNC Eshelman School of Pharmacy, 2215 Kerr Hall, Chapel Hill, NC 27599-7573, USA. ${ }^{2}$ The University of Texas at Austin, College of Pharmacy, Austin, TX, USA. ${ }^{3}$ The University of Texas Health Science Center San Antonio, School of Medicine, San Antonio, TX, USA.

Received: 13 April 2014 Accepted: 23 September 2014

Published: 10 October 2014

\section{References}

1. Linas BP, Wang B, Smurzynski M, Losina E, Bosch RJ, Schackman BR, Rong J, Sax PE, Walensky RP, Schouten J, Freedberg KA: The impact of HIV/HCV co-infection on health care utilization and disability: results of the ACTG Longitudinal Linked Randomized Trials (ALLRT) Cohort. J Viral Hepat 2011, 18(7):506-512.

2. Katzenstein DA, Hammer SM, Hughes MD, Gundacker $H$, Jackson JB, Fiscus S, Rasheed S, Elbeik T, Reichman R, Japour A, Merigan TC, Hirsch MS: The relation of virologic and immunologic markers to clinical outcomes after nucleoside therapy in HIV-infected adults with 200 to 500 CD4 cells per cubic millimeter. AIDS Clinical Trials Group Study 175 Virology Study Team. N Engl J Med 1996, 335(15):1091-1098.

3. McHutchison JG, Gordon SC, Schiff ER, Shiffman ML, Lee WM, Rustgi VK, Goodman ZD, Ling MH, Cort S, Albrecht JK: Interferon alfa-2b alone or in combination with ribavirin as initial treatment for chronic hepatitis $C$. Hepatitis Interventional Therapy Group. N Engl J Med 1998, 339(21):1485-1492. 
4. Torriani FJ, Rodriguez-Torres M, Rockstroh JK, Lissen E, Gonzalez-Garcia J, Lazzarin A, Carosi G, Sasadeusz J, Katlama C, Montaner J, Sette H Jr, Passe S, De Pamphilis J, Duff F, Schrenk UM, Dieterich DT: Peginterferon Alfa-2a plus ribavirin for chronic hepatitis $\mathrm{C}$ virus infection in HIV-infected patients. N Engl J Med 2004, 351(5):438-450.

5. Ananthakrishnan AN, McGinley EL, Fangman J, Saeian K: Hepatitis C/HIV co-infection is associated with higher mortality in hospitalized patients with hepatitis C or HIV. J Viral Hepat 2010, 17(10):720-729.

6. Gebo KA, Diener-West M, Moore RD: Hospitalization rates differ by hepatitis C status in an urban HIV cohort. J Acquir Immune Defic Syndr 2003, 34(2):165-173.

7. Backus LI, Boothroyd D, Deyton LR: HIV, hepatitis C and HIV/hepatitis C virus co-infection in vulnerable populations. AIDS 2005, 19(Suppl 3):S13-S19.

8. Myers RP, Liu M, Shaheen AA: The burden of hepatitis $C$ virus infection is growing: a Canadian population-based study of hospitalizations from 1994 to 2004. Can J Gastroenterol 2008, 22(4):381-387.

9. Ly KN, Xing J, Klevens RM, Jiles RB, Ward JW, Holmberg SD: The increasing burden of mortality from viral hepatitis in the United States between 1999 and 2007. Ann Intern Med 2012, 156(4):271-278.

10. Sie L, Gatto NM, Bancroft E: Hospitalizations due to hepatitis C in Los Angeles County, 2007-2009: case characteristics and factors associated with mortality. J Viral Hepat 2013, 20(9):628-637.

11. Workowski KA, Berman S, Centers for Disease C, Prevention: Sexually transmitted diseases treatment guidelines, 2010. MMWR Recomm Rep 2010, 59(RR-12):1-110.

12. Ghanem KG, Moore RD, Rompalo AM, Erbelding EJ, Zenilman JM, Gebo KA: Lumbar puncture in HIV-infected patients with syphilis and no neurologic symptoms. Clin Infect Dis 2009, 48(6):816-821.

13. Panel on Opportunistic Infections in HIV-Infected Adults and Adolescents. Guidelines for the prevention and treatment of opportunistic infections in HIV-infected adults and adolescents: recommendations from the Centers for Disease Control and Prevention, the National Institutes of Health, and the HIV Medicine Association of the Infectious Diseases Society of America. 115F [http://aidsinfo.nih.gov/contentfiles/lvguidelines/adult_oi.pdf]

14. Strader DB: Coinfection with HIV and hepatitis $C$ virus in injection drug users and minority populations. Clin Infect Dis 2005, 41(Suppl 1):S7-S13.

15. Jacobson IM, McHutchison JG, Dusheiko G, Di Bisceglie AM, Reddy KR, Bzowej NH, Marcellin P, Muir AJ, Ferenci P, Flisiak R, George J, Rizzetto M, Shouval D, Sola R, Terg RA, Yoshida EM, Adda N, Bengtsson L, Sankoh AJ Kieffer TL, George S, Kauffman RS, Zeuzem S: Telaprevir for previously untreated chronic hepatitis C virus infection. N Engl J Med 2011, 364(25):2405-2416

16. Poordad F, McCone J Jr, Bacon BR, Bruno S, Manns MP, Sulkowski MS, Jacobson IM, Reddy KR, Goodman ZD, Boparai N, DiNubile MJ, Sniukiene V, Brass CA, Albrecht JK, Bronowicki JP: Boceprevir for untreated chronic HCV genotype 1 infection. N Engl J Med 2011, 364(13):1195-1206.

17. FDA Approval: Olysio (simeprevir) for the treatment of chronic hepatitis $C$ in combination antiviral treatment. [http://www.fda.gov/NewsEvents/ Newsroom/PressAnnouncements/ucm376449.htm]

18. FDA Approval: Approval of Sovaldi (sofosbuvir) tablets for the treatment of chronic hepatitis C. [http://www.fda.gov/NewsEvents/Newsroom/ PressAnnouncements/ucm377888.htm]

doi:10.1186/1471-2334-14-536

Cite this article as: Oramasionwu et al:: National trends in hospitalization and mortality rates for patients with HIV, HCV, or HIV/HCV coinfection from 1996-2010 in the United States: a cross-sectional study. BMC Infectious Diseases 2014 14:536.

\section{Submit your next manuscript to BioMed Central and take full advantage of:}

- Convenient online submission

- Thorough peer review

- No space constraints or color figure charges

- Immediate publication on acceptance

- Inclusion in PubMed, CAS, Scopus and Google Scholar

- Research which is freely available for redistribution

Submit your manuscript at www.biomedcentral.com/submit 